\title{
Keywords, Lexical Cohesive Devices and the Impact of Search Engine Result for Tour Websites
}

\author{
I Gusti Ngurah Adi Rajistha'; Dewa Ayu Kadek Claria²; Anak Agung Istri Manik \\ Warmadewi ${ }^{3}$ and I Gusti Ayu Agung Dian Susanthi ${ }^{4}$ \\ \{ngurah.adi.rajistha@gmail.com ${ }^{1}$; clariadewaayu@gmail.com²; manikwarmadewi@gmail.com ${ }^{3}$ and \\ gungdian03@gmail.com ${ }^{4}$ \} \\ Faculty of Letters, Universitas Warmadewa, Denpasar-Bali, Indonesia
}

\begin{abstract}
Content and some elements related to a website are important parts for the website. However, the owners of the website sometimes are not aware of the content and those elements that actually could attract the reader. This study aims to describe the lexical cohesive devices supporting the keywords in the website domain, website title, meta keyword, meta description, heading, content, links, and image title. The data used were words, phrases, clauses and sentences found in the websites. In collecting the data, keywords everywhere and lsigraph.com were used to find the related keywords and the google monthly search (August 2018). Then the data were analyzed descriptively by distributional method. The theory applied was the theory of lexical cohesion proposed by Halliday. Finally, the result of the analysis was presented by formal and informal method. The result shows both reiteration and collocation were found in the tour websites. In brief, the use of lexical cohesive devices can be the first step in designing contents of website by optimizing the keywords.
\end{abstract}

Keywords: Elements of website; keywords; lexical cohesion; tour websites

\section{Introduction}

Tourism is the aspect which has a very rapid development especially in Bali. Nowadays, the use of websites to promote the tour packages is one of many ways to improve the tourism sector. Beside the use of image, the use of text is a must in the website in order to be indexed by search engine, such as google.com. In this case, the roles of language could be said very important. Flergin explained advertising as textual and visual communication. In addition, he said that textual level involving lexical and grammatical while visual level involving figures and images [1]. The impact of online media can be seen in Salehi and Farahbakhsh's study. They found that the most effective tool for promotional strategies are handbook, internet advertising, TV, brochure and newspaper [2]. Pop declared the cultural tourism advertising as a hybrid register. This study applied a functional linguistics analysis and compared advertising-specific and tourism-specific grammar in a text for cultural tourism [3]. D'Angella and De Carlo explained that the effective websites should be managed by cities, well informed to the worldwide web, and managed by mass market destinations. However, this study shows no significant relationships between tourism development and websites' effectiveness [4]. This shows online media could be one of some effective media to promote tourism.

Promoting through online media cannot be separated from website. Then, the website consists of contents to read or view in the form of text or image. In the form of text, the 
contents should be coherent and cohesive devices are the choice. Moris and Hirst explained that the lexical chains provide an important indicator of text structure. It also provides a semantic context for interpreting words, concepts, and sentences [5]. This study shows the importance of lexical cohesion as a concept of lexical chains. Furthermore, they believe that lexical cohesion is useful both as a theory and as a practical tool for determining both the commonly agreed on and the subjective aspects of text understanding [6]. Schiller investigates the nature of cohesion on a website and the implications for the website translator. In this study it is explained that the importance of repetition both exact or simple one in an online environment. It is usually expressed in the form of keywords or keywords phrases [7]. The concept of lexical chains is also used by Remus. He examines the suitability of statistical methods for the task of identifying lexicon-semantic relations in order to build proper lexical chains. The statistical methods were examined for their applicability for identification of lexical chains in a cohesive text [8].

Creating content for an international website relates to the way how we learn and write in English. The elements in the text that will be made should be unity and relates each other. In this case, the meaning conveyed could be received well by the reader. Hameed examined the overall meaning of a text is contributed by the relevance of cohesive used. In this case, it is explained that cohesive devices in a text create a semantic relation that is used to decode the overall meaning [9]. Huang, Song and Li carried out the importance of lexical cohesion in improving English reading ability. They described that lexical cohesion is one of ways to make a text coherent [10]. Crosthwaite found that scaffolding helps L2 learners to create and hold more accurate reference to discourse referents, and instances of unscaffolded narrative discourse present increased difficulty for the L2 speaker. It means that L2 learners have more difficulty managing accurate reference maintenance, the overall coherence of their discourse is reduced [11]. Ahmed in his dissertation examines lexical cohesion and schematic structure in research articles on Islam and science by a systemic functional investigation. This study investigates the structure of those texts through the perspective of lexical cohesion and schematic structure. This research also proved that repetition is the most used lexical relation [12]. Haris and Yunus revealed that the lexical cohesion created cohesiveness towards the ideas conveyed by students in writing [13].

The content and the use of keywords on the tour websites are very interesting to be analyzed, since the owner of the website, sometimes does not concern on the use of language in the content, and on choosing and optimizing the keywords. This case leads to the possibility of indexing on a good page position by google excluding the external factors like promoting websites by google adsense. Generally, although the position of websites could be determined by external factors of the website, however, the internal factors are also important to be analyzed. The internal factors could be the language used to express the content in the website. In brief, this study focuses on the lexical cohesive devices that support the keywords in the website.

The data of this study are some tour websites taken from three keywords that were mostly searched on August 2018. In this case, the data of this study were searched in the website domain, website title, meta keywords, meta description, heading, content, links, image title. It is important to describe the tour website meant in this study, it is the website that 1) provides tour packages in Bali so it is not just an information website or a website that gives a review to other websites, 2) is had by individual or company, and 3) is showed on the first and second page of google search. In addition, ads showing tour website is also not used.

In collecting the data, there are two tools used: keywords everywhere, that is an extension on chrome, and lsigraph.com, that is a website for latent semantic indexing. The first step 
done was determining the main keyword that is Bali tour. The second step was determining related keywords through lsigraph.com and was also supported by keywords everywhere so there are top three keywords used: Bali package, Bali tour packages and Bali tour. Some websites by using random sampling were taken for each keyword. Then the websites were classified based on the monthly search of tour website. The data were collected by reading the content repeatedly. The data in the website coding were collected by inspecting it first.

The data of this study were analyzed descriptively by using distributional method. In this case, the content of the tour website in the form of words, phrases, clauses and sentences were analyzed by using lexical cohesion theory proposed by Halliday [14]. Finally, formal and informal methods were used in presenting the result and discussion. The formal method used was by using tables and the informal one was by using sentences to discuss the result of the analysis.

\section{Discussion}

The mechanisms in creating a coherent text on a website are not different from creating a coherent text traditionally [15]. The use of keywords to improve the possibility of indexing is organized well. Language as the internal factors of the website is used efficiency. In this case, the use of lexical cohesive devices that support the keywords in the websites is applied well. The following tables show the result of the analysis of lexical cohesive devices on the three keywords 'Bali package', 'Bali tour packages', and 'Bali tour'.

Table 1. Lexical cohesive device on keyword 'Bali package'.

\begin{tabular}{|c|c|c|c|c|}
\hline \multicolumn{2}{|c|}{ Lexical cohesive devices } & \multirow[t]{2}{*}{ Bali } & \multirow[t]{2}{*}{ Package } & \multirow[t]{2}{*}{ Place of findings } \\
\hline 1) $\mathrm{I}$ & Reiteration & & & \\
\hline & a) Repetition & + & + & $\begin{array}{l}\text { Bali: website domain, website title, meta } \\
\text { keywords, meta description, heading (h1, h2, } \\
\text { h3), content, links, image title } \\
\text { Package: website domain, website title, meta } \\
\text { keywords, meta description, heading (3), } \\
\text { content, links, image title }\end{array}$ \\
\hline & Synonym & - & + & Package: content \\
\hline & Superordinate & + & - & Bali: content \\
\hline & d) General word & - & - & - \\
\hline 2) & Collocation & + & + & Bali: content; Package: content \\
\hline
\end{tabular}

Table 2. Lexical cohesive devices on keyword 'Bali tour packages'.

\begin{tabular}{|c|c|c|c|c|c|}
\hline \multicolumn{2}{|c|}{ Lexical cohesive devices } & \multirow[t]{2}{*}{ Bali } & \multirow[t]{2}{*}{ Tour } & \multirow[t]{2}{*}{ Packages } & \multirow[t]{2}{*}{ Place of findings } \\
\hline 1) & Reiteration & & & & \\
\hline & a) Repetition & + & + & + & $\begin{array}{l}\text { Bali: website domain, website title, meta } \\
\text { keywords, meta description, heading (h1, } \\
\text { h2, h3), content, links, image title } \\
\text { Tour: website domain, website title, meta } \\
\text { keywords, meta description, heading (h1, } \\
\text { h2, h3), content, links, image title } \\
\text { Packages: website domain, website title, } \\
\text { meta keywords, meta description, heading }\end{array}$ \\
\hline
\end{tabular}




\begin{tabular}{llllll}
\hline & & & & & (h1, h2), content, links, image title \\
\hline b) & Synonym & - & + & - & Tour: meta keywords, content \\
\hline c) & Superordinate & + & - & - & Bali: content \\
\hline d) & General word & - & + & - & Tour: content \\
\hline 2) & Collocation & + & + & + & $\begin{array}{l}\text { Bali: content; Tour: content; Packages: } \\
\text { content }\end{array}$ \\
\hline
\end{tabular}

Table 3. Lexical cohesive devices on keyword 'Bali tour'.

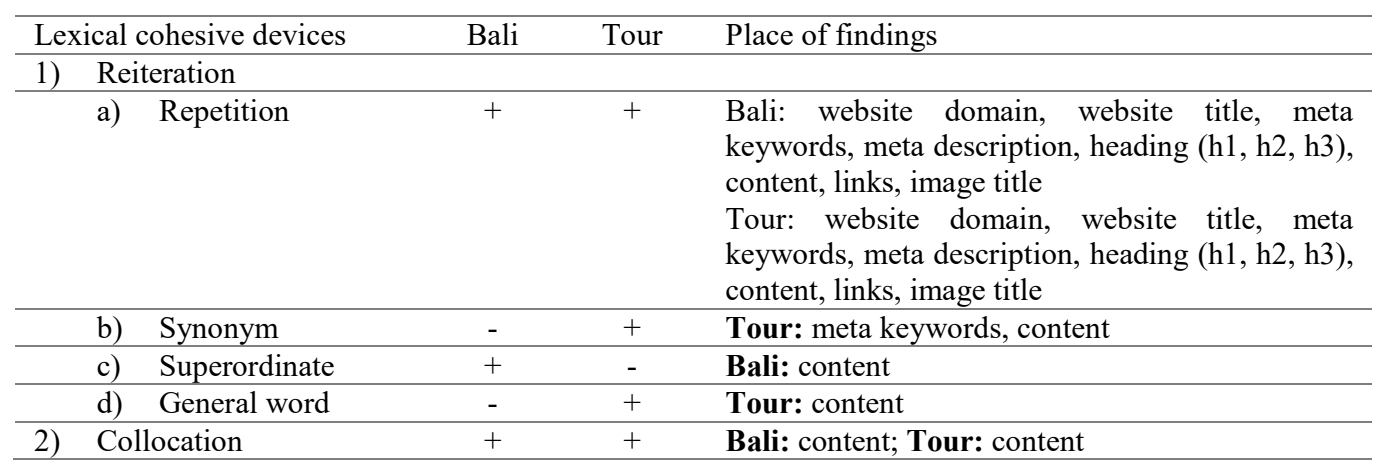

The device that is mostly applied is repetition. The keywords that become the important point of a website are repeated many times in different part of website. Other devices are also used but the use is not as often as repetition. This study support the argument of Schiller that explained repetition as an important cohesive device in a website [7].

The relation between lexical items that makes a text coherent is the key of writing a content of website. The lexical cohesive devices that support the keywords show lexical coherence, although the lexicon is placed in a different part of website. Based on the result of the analysis, the use of reiteration, in this case the repetition that supports the keywords is displayed in every part of website. For example: the word Bali and tour repeat in every part of the website 'http://www.balicheapesttours.com/'.

Table 4. Repetition of word Bali and tour.

\begin{tabular}{|c|c|c|}
\hline No. & Website parts & Data found \\
\hline 1. & Website domain & www.balicheapesttours.com \\
\hline 2. & Website title & Cheap Bali Tours \& Holiday Packages for Budget Travellers \\
\hline 3. & Meta keywords & $\begin{array}{l}<\text { meta name }=" \text { "keywords" content }=\text { "bali, bali tour, bali tours, bali trip, bali } \\
\text { packages, bali tour package, bali tours package, bali holiday packages, bali } \\
\text { travel packages, bali trip package, bali package deals, cheap bali tour, } \\
\text { cheap bali holiday packages" }>\end{array}$ \\
\hline 4. & Meta description & $\begin{array}{l}<\text { meta name="description" content="Find Here Cheap Bali Tours \&amp; } \\
\text { Holiday Packages - Easy \&amp; Secure Booking - No Advance Payment } \\
\text { Required - Free Cancellation!"> }\end{array}$ \\
\hline 5. & Heading & $\begin{array}{l}\text { H1: Cheap Bali Tours \& Holiday Packages } \\
\text { H2: Cheap Bali Tours \& Holiday Packages for Budget Travellers } \\
\text { H3: Discover cheap holiday deals with Bali Cheapest Tours }\end{array}$ \\
\hline 6. & Content & $\begin{array}{l}\text { At Bali Cheapest Tours, we specially design itineraries to uncover both the } \\
\text { scenic beauty and cultural charm of Bali while offering ample opportunity } \\
\text { for personalized discovery. We can customize each of our Bali tour } \\
\text { package itineraries to match your preferred travel period, touring needs and }\end{array}$ \\
\hline
\end{tabular}




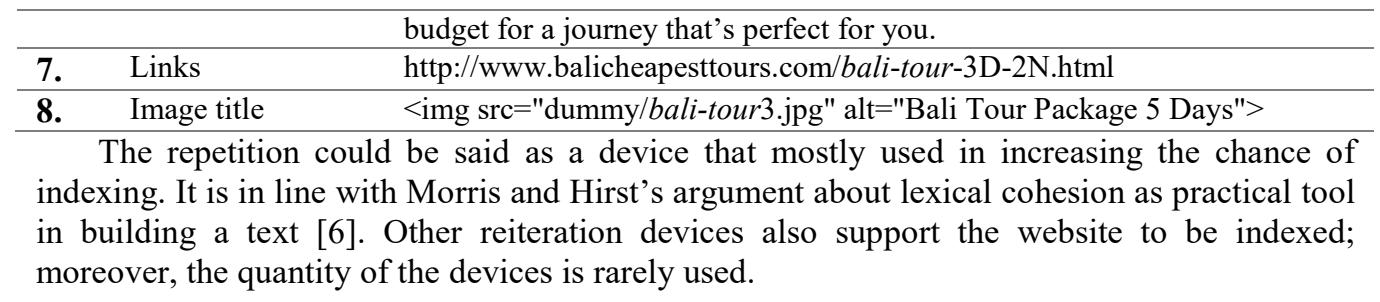

Table 5. Other kinds of reiteration used.

\begin{tabular}{|c|c|c|c|}
\hline No. & Kinds of reiteration & Website parts & Data found \\
\hline \multirow[t]{2}{*}{1.} & Synonym & $\begin{array}{l}\text { Meta } \\
\text { keywords }\end{array}$ & $\begin{array}{l}<\text { meta name="keywords" content="bali, bali tour, bali } \\
\text { tours, bali trip, bali packages, bali tour package, bali } \\
\text { tours package, bali holiday packages, bali travel } \\
\text { packages, bali trip package, bali package deals, cheap } \\
\text { bali tour, cheap bali holiday packages" }> \\
\text { (http://www.balicheapesttours.com/) }\end{array}$ \\
\hline & & Content & $\begin{array}{l}\text { Fourth Day in program Bali Tour Packages } 5 \text { Days and } \\
4 \text { Nights is to enjoy visit the famous Jatiluwih Rice } \\
\text { Terrace and see the amazing sunset at Tanah Lot } \\
\text { Temple. Before start the trip you will enjoy breakfast at } \\
\text { hotel, our driver will pick up at lobby and start the } \\
\text { journey to explore the beauty tourism site in this } \\
\text { itinerary (http://www.baligoldentour.com/bali-tour- } \\
\text { packages-5-days-4-nights.php) }\end{array}$ \\
\hline 2. & Superordinate & Content & $\begin{array}{l}\text { With the right Bali holiday package, you are in for an } \\
\text { exceptional and wonderful island stay to remember and } \\
\text { cherish for all of your life. (https://7.holiday/packages) }\end{array}$ \\
\hline 3. & General word & Content & 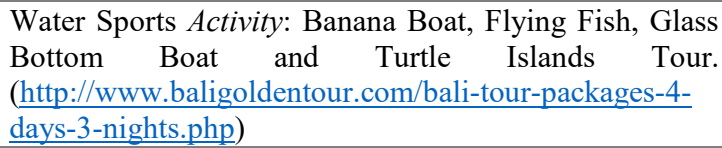 \\
\hline
\end{tabular}

The use of synonym can be seen in three parts of the website. In the meta keywords, the words that have similar or near similar meaning are tour, trip, and travel. The use of the words increases the possibility of indexing because the customer might search Bali tour, Bali trip or Bali travel. The use of superordinate also helps the website to make itself different from others, such as from other information about Bali for example its history. Then the general word activity describes the website that it is a tour website, consisting of some tour packages. The collocation is the last devices increasing the possibility of indexing. For example: the use of related words: Bali, package, tour, and activities showing the promotion of the website product. The use of those words could be seen below.

The Bali Package is a legal tour company in Bali delighted to offers you Package deals for Tours, activities and adventures, Combination tours package in Bali. We offer you a complete Bali Tours Holidays Packages designed with the best tours, activities and adventures in Bali. (https://www.thebalipackage.com/)

\section{Conclusion}


Based on the result and discussion above, it can be concluded that the most important thing is supporting the keywords by applying lexical cohesive devices. The use of repetition is mostly used by the developer and the owner of website to increase the possibility of indexing excluding the external factors. Moreover, cohesion and coherence are very important in optimizing information transfer and search engine indexing.

\section{References}

[1] Flergin, A.: anguage of persuasion: A discourse approach to advertising language. Res. J. Recent Sci. Vol. 3. pp. 62-68 (2014)

[2] Salehi, H and Farahbakhsh, M.: Tourism advertisement management and efective tools in tourism industry. Int. J. Geogr. Geol. Vol. 3 (10). pp. 124-134 (2014)

[3] Pop, A.: The cultural tourism advertising as a hybird register. Philologia. Vol. 3 (2). pp. 169 177 (2008)

[4] D'Angella, F and De Carlo, M.: Linking online communication strategies to destinations' performance: An explorative. Int. J. Hosp. Tour. Vol. 1 (2). pp. 19-28 (2012)

[5] Morris, J and Hirst, G.: Lexical cohesion computed by thesaural relations as an indicator of the structure of text. Comput. Linguist. Vol. 17 (1). pp. 21-48 (1991)

[6] Morris, J and Hirst, G.: The subjectivity of lexical cohesion in text. Am. Assoc. Artif. Intellegence (2004)

[7] Schiller, A.: Aspects of cohesion in web site translation: A translator's perspective. Dublin City University (2008)

[8] Remus, S.: Automatically identifyying lexical chains by means of statistical methods - a knowledge - free approach. Technische Universitat (2012)

[9] Hameed, H, T.: Cohesion in texts: A discourse analysis of a news article in a magazine. ALFaith J. Vol. 37. pp. 81-114 (2008)

[10] Huang, M., Song, Y and Li, N.: A study on the application of lexical cohesion to ESL reading based on web materials. CSEE. pp. 433-438 (2011)

[11] Crosthwaite, P.: The effect of collaboration on the cohesion and coherence of L2 narrative discourse between English NS and Korean L2 English users. Asian EFL J. Vol. 13 (4). pp. 135-166 (2011)

[12] Ahmed, A, A, A.: A systemic functional investigation of lexical cohesion and schematic structure in reserach articles on Islam and science. University of Malaya (2013)

[13] Haris, S, N, F and Yunus, M, M.: The use of lexical cohesion among TESL post graduate students in academic writing. J. Educ. Hum. Dev. Vol. 3 (2). pp. 874-869 (2014)

[14] Halliday, M, A, K and Hasan, R.: Cohesion in english. London: Longman Group Ltd (1976)

[15] Degano, C.: Textuality on the web: A focus on argumentative text types. IGI Glob. pp. 414$436(2014)$ 